\title{
Changes in Neurotrophin Levels in Umbilical Cord Blood From Infants With Different Gestational Ages and Clinical Conditions
}

\author{
NITIN S. CHOUTHAI, JACKIE SAMPERS, NIRMALA DESAI, AND GEORGE M. SMITH \\ Division of Neonatology, Departments of Pediatrics [N.S.C., J.S., N.D.] and Physiology [G,M.S.], \\ University of Kentucky Medical Center, Lexington, KY 40502, U.S.A.
}

\begin{abstract}
ABST
Apoptotic neuronal loss may be responsible for altered brain
development associated with prematurity and perinatal insults.
Neurotrophins play crucial roles in protecting neurons from
entering or progressing along an apoptotic pathway. The present
study examined levels of neurotrophins in human umbilical cord
blood from infants at different gestational ages and clinical
conditions. We collected 60 samples of cord blood and catego-
rized them accordingly into three gestational age groups: group
A (24-28 wk), group B (29-35 wk), and group C ( $\geq 36$ wk).
Neurotrophin levels were determined by using brain-derived
neurotrophic factor (BDNF) and neurotrophin 3 (NT3) ELISA.
Clinical data were obtained by medical chart analysis. The
BDNF levels were $884 \pm 386,1421 \pm 616$, and $2190 \pm 356$
pg/mL in group A, group B, and group C, respectively. Signif-
icant differences were found between groups A and B ( $p=$
0.038), groups A and C ( $p=0.0001)$, and groups B and C ( $p=$
$0.001)$ Infants with severe intraventricular hemorrhage had sig-
nificantly lower cord blood BDNF levels $(925 \pm 513$ pg/mL)
\end{abstract}
compared with their normal counterparts $(1650 \pm 674 \mathrm{pg} / \mathrm{mL} ; p$ $=0.021)$. NT3 levels did not show significant change either across gestational ages or with the presence of intraventricular hemorrhage. Cord blood levels of BDNF may reflect the degree of neural maturity in premature infants. Interestingly, when a complete course of antenatal steroids was given, BDNF and NT3 cord blood levels were higher than when no steroid was given. Increased neurotrophins levels may also mediate improved neurodevelopmental outcome in infants who received antenatal steroids. (Pediatr Res 53: 965-969, 2003)

Abbreviations
BDNF, brain-derived neurotrophic factor
NT3, neurotrophin 3
IVH, intraventricular hemorrhage
PROM, premature rupture of membranes
SGA, small for gestational age
PIH, pregnancy-induced hypertension

There has been tremendous progress in technology for prenatal and neonatal care during the past decade. These improvements have increased the survival of extremely premature infants. Multiple factors play a role in neurodevelopmental outcome of these prematurely born infants. Pregnancy-induced hypertension (PIH), chorioamnionitis, premature rupture of membranes (PROM), and maternal smoking significantly alter intrauterine conditions that lead to small for gestational age (SGA) status, and also may alter the neurodevelopmental outcome of prematurely born infants (1-6). Mothers expected to have premature delivery are often given antenatal steroids to improve pulmonary maturity. These steroids have been shown to improve neurodevelopmental outcome (7). Increased sur-

Received August 6, 2002; accepted January 8, 2003.

Correspondence: Nitin Shashikant Chouthai, M.D., Department of Pediatrics, University of Arizona Health Sciences Center, Rm 3335, 1501 N Campbell Avenue, P.O. Box 245073, Tucson, AZ 85724, U.S.A.; e-mail: chouthai@email.arizona.edu

This work was supported by Children's Miracle Network grant, Children's Hospital, University of Kentucky, Lexington.

DOI: 10.1203/01.PDR.0000061588.39652.26 vival of such prematurely born infants is still associated with some neurodevelopmental morbidities, ranging from behavioral disturbances (e.g. attention-deficit/hyperactivity disorder) to cerebral palsies of varying severity (8).

Infants born before $32 \mathrm{wk}$ gestation have less cortical gray matter when measured at corrected term postconceptional age compared with full-term infants measured at birth (9). The mechanism of the altered development is predicted to be a process of apoptotic neuronal loss or damage. The actual volume of cortical gray matter of infants born between 29 and $35 \mathrm{wk}$ gestation measured at birth shows a progressive increase with length of gestation up to 4-fold (10). This period is a critical phase of neurodevelopment and may be an important consideration for infants born prematurely. It is thus important to analyze the neurophysiologic milieu at this stage of development.

Neurotrophic factors play crucial roles in neuroprotection. Neurotrophins promote survival and can reduce apoptosis in many populations of neurons (11). Nerve growth factor, brain derived neurotrophic factor (BDNF), and neurotrophin 3 (NT3) 
are neurotrophins that act on tyrosine kinase (Trk) A, Trk B, and Trk $\mathrm{C}$ receptors, respectively. In addition to antiapoptotic activities, neurotrophins play important roles in axon growth during development (12), higher neuronal functions (13), morphologic differentiation, and neurotransmitter expression (14). Thus, neurotrophins may play important roles in antenatal and postnatal brain development. However, data regarding the presence and influence of neurotrophins in prematurely born infants are insufficient. The cerebrospinal fluid levels of BDNF were higher when measured in infants who had hypoxic ischemic insults compared with their normal counterparts (15). In addition, BDNF has been demonstrated to decrease tissue loss in brain when administered after hypoxic-ischemic injury in neonatal animals $(16,17)$. Circulating BDNF levels correlate with cortical BDNF levels in newborn rats (18). Nerve growth factor levels measured in umbilical cord blood were higher in samples from infants born at term compared with those obtained from preterm infants (19). There are no available data described about changes in trends of BDNF and NT3 levels with increasing gestational age or after birth in humans. Thus, questions remain concerning the presence and significance of neurotrophins during the perinatal period and especially in relation to factors that may cause neurologic insults in the developing brain. Proposed initial steps to address these questions involve analyzing neurotrophin levels in umbilical cord blood, which might represent their milieu during the intrauterine phase of brain development at various gestational ages. Because the blood-brain barrier at this stage is still immature, these blood levels may also represent neurotrophin concentrations in the CNS (20). This study was designed to measure BDNF levels and NT3 levels at different gestational ages in human umbilical cord blood to investigate the hypothesis that neurotrophin levels differ at different gestational ages. In addition, we looked at differences in neurotrophin levels in the presence and absence of factors that may affect intrauterine conditions and thus neurodevelopmental outcome.

\section{METHODS}

Samples and neurotrophin ELISA. This study was reviewed and approved by the Medical Institutional Review Board, University of Kentucky, Lexington (Protocol 01-351$\mathrm{P} 2 \mathrm{R}$ ). The samples were divided into three groups according to gestational ages. Umbilical cord blood specimens were collected from group A (24-28 wk; $n=11)$, group B (29-35 wk; $n=33)$, and group $\mathrm{C}$ ( $\geq 36 \mathrm{wk} ; n=16)$. The subjects were consecutively born infants at University of Kentucky, Lexington, which cares for approximately 2000 deliveries a year and is equipped with a level 3 neonatal intensive care unit. The sample collection was done using complete aseptic precautions. A wide bore needle was inserted into an umbilical vessel, and approximately 5 to $10 \mathrm{~mL}$ of blood was drawn into a sterile syringe. This blood then was transported to the blood bank, where it was centrifuged to separate the serum. The specimens were stored at $-80^{\circ} \mathrm{C}$. BDNF and NT3 levels were determined by using ELISA kits from $\mathrm{R} \& \mathrm{D}$ Systems in triplicate. Appropriate controls were used to eliminate errors caused by background (21). One control was without biotinylated sec- ondary antibody. This control accounts for the endogenous peroxidase activity of plasma and $\mathrm{Hb}$ (in hemolyzed specimens). A second control was without the antigen and accounts for the possibility of contamination of either primary or secondary antibody with BDNF. We analyzed 50 samples for BDNF levels and 30 samples for NT3 levels. We also had 20 samples with both BDNF and NT3 levels.

Clinical data. Clinical data, including birth weight, sex, head circumference, and gestational age at birth, were recorded. Antenatal history regarding chorioamnionitis, prolonged PROM, PIH, SGA status, antenatal steroids, and maternal smoking was obtained. Postnatal head ultrasound results were also obtained. Grading of intraventricular hemorrhage (IVH) was done using Papile's classification (22). Infants with IVH grades 1 and 2 were classified as having mild head bleeds, and those with grades 3 and 4 IVH were classified as having moderate to severe bleeds. Clinical chorioamnionitis was defined according to the criteria proposed by Gibbs et al. (23). The diagnosis required a temperature elevation to $37.8^{\circ} \mathrm{C}$ and two or more of the following criteria: uterine tenderness, malodorous vaginal discharge, maternal tachycardia, fetal tachycardia, and leukocytosis. Leukocytosis was defined as a white blood cell count $>15,000 / \mathrm{mm}^{3}$ (24). The SGA status was defined as birth weights $<10$ centiles (25). The gestational age was derived by antenatal ultrasound when done between 13 and 24 wk using Campbell dating standard (26), crown-rump length, or the femur length $(27,28)$. The Ballard score $(29,30)$ was used when ultrasound estimation was not available (31).

Statistical analysis. Statistical analysis was done using SPSS statistical package. One-way ANOVA followed by Scheffe post hoc analysis and $t$ test was used to determine differences among the groups. Fischer exact test was also used to compare occurrences of clinical parameters within different groups. Pearson correlation was used to determine the relationships between BDNF and NT3 levels.

\section{RESULTS}

Subject description. The differences among groups A (24-28wk), B (29-35 wk), and C ( $\geq 36 \mathrm{wk}$ ) were statistically significant for birth weight and head circumferences for the subject population (Table 1). Distribution of boys and girls was not significantly different among the gestational age groups. The differences among the occurrences of chorioamnionitis, $\mathrm{PIH}$, or SGA were not statistically significant in different gestational age groups. Occurrence of PROM was significantly higher in group B, whereas occurrence of smoking was significantly higher in group A.

Neurotrophin levels at different gestational ages. The differences between BDNF levels when compared across gestational age groups demonstrated a significant increase with increased age (group A, $884 \pm 386 \mathrm{pg} / \mathrm{mL}$; group B, $1421 \pm$ $616 \mathrm{pg} / \mathrm{mL}$; group C $2190 \pm 357 \mathrm{pg} / \mathrm{mL}$ ); these data were statistically significant $(p=0.0001)$ using one-way ANOVA (Fig. 1). The BDNF level differences between groups A and $\mathrm{B}$ $(p=0.038)$, groups $\mathrm{B}$ and $\mathrm{C}(p=0.001)$, and groups $\mathrm{A}$ and $\mathrm{C}$ ( $p=0.0001)$ were also statistically significant using Scheffe post hoc analysis. In contrast, NT3 levels in group A (238 \pm 
Table 1. Subject description $(\mathrm{n}=60)$

\begin{tabular}{|c|c|c|c|c|}
\hline Parameters & Group A & Group B & Group C & $P$ value \\
\hline$n$ & 11 & 33 & 16 & \\
\hline Birth weight (g) & $816.36 \pm 80$ & $1611.34 \pm 70$ & $3241.42 \pm 255$ & 0.0001 \\
\hline Head circumference $(\mathrm{cm})$ & $23.34 \pm 0.58$ & $28.86 \pm 0.34$ & $35.42 \pm 1.7$ & 0.0001 \\
\hline Boys & 4 & 22 & 7 & 0.448 \\
\hline PROM & 3 & 12 & 0 & 0.011 \\
\hline Chorioamnionitis & 2 & 2 & 0 & 0.204 \\
\hline Smoking & 6 & 6 & 0 & 0.002 \\
\hline
\end{tabular}

\section{BDNF Levels at Different Gestational Age Groups}

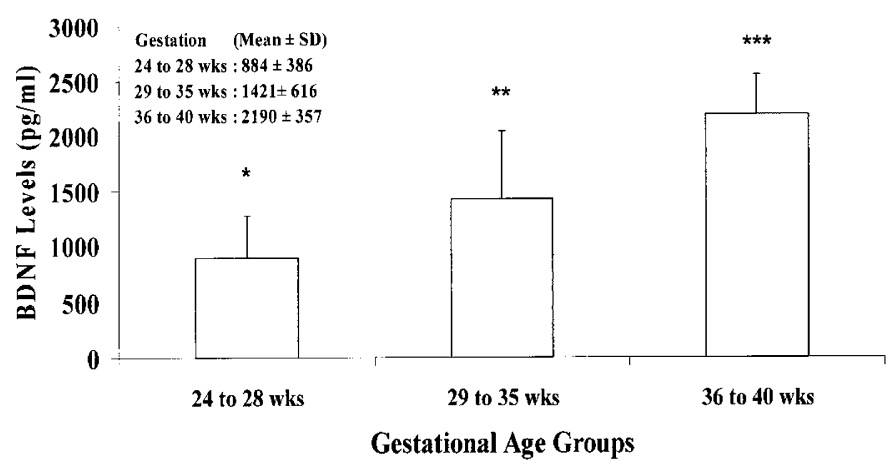

Figure 1. Differences between groups A and B $\left({ }^{*} p=0.038\right)$, groups $\mathrm{B}$ and $\mathrm{C}(* * p=0.001)$, and groups $\mathrm{A}$ and $\mathrm{C}(* * * p=0.0001)$ are statistically significant.

$84.5 \mathrm{pg} / \mathrm{mL})$, group B $(281 \pm 130 \mathrm{pg} / \mathrm{mL})$, and group C $(211$ $\pm 131 \mathrm{pg} / \mathrm{mL}$ ) did not differ across gestational age groups. NT3 levels also did not correlate with BDNF levels across gestational ages by Pearson correlation test $(p=0.723)$. BDNF levels seem to increase with increasing gestational ages, whereas NT3 levels remain unchanged.

Neurotrophin levels and clinical variables. We compared BDNF and NT3 levels in the presence and absence of all clinical variables. BDNF levels were higher in girls $(n=21$; $1605 \pm 650 \mathrm{pg} / \mathrm{mL})$ than in boys $(n=29 ; 1439 \pm 701 \mathrm{pg} / \mathrm{mL})$ but did not reach statistical significance. NT3 levels were also higher in girls $(n=16 ; 271 \pm 113 \mathrm{pg} / \mathrm{mL})$ than in boys $(n=$ $14 ; 246 \pm 115 \mathrm{pg} / \mathrm{mL}$ ) but again without statistical significance. Similar trends, without statistical significance, were observed when neurotrophin levels of boys and girls were compared within gestational groups. BDNF levels in the presence of chorioamnionitis $(651 \pm 401 \mathrm{pg} / \mathrm{mL})$ were lower as compared with those without chorioamnionitis $(1349 \pm 598$ $\mathrm{pg} / \mathrm{mL})$ and trended toward statistical significance $(p=0.056)$. The presence of PROM, PIH, SGA, or maternal smoking did not seem to alter either BDNF or NT3 levels significantly.

Neurotrophins and antenatal steroids. Sixteen (49\%) subjects in group B had received a complete course of antenatal steroids, whereas only $2(18 \%)$ subjects in group A and none in group $\mathrm{C}$ had received a complete course of antenatal steroids $(p$ $=0.0001$ ). Only mothers who had been pregnant $<32 \mathrm{wk}$ were given antenatal steroids. Thus, neurotrophin levels from infants with $<32 \mathrm{wk}$ gestation were considered for further analysis ( $n$ $=30)$. BDNF levels were significantly higher $(p=0.029)$ in samples from subjects who received a complete course of antenatal steroids $(1527 \pm 591 \mathrm{pg} / \mathrm{mL})$ compared with those who received only one dose of steroids $(1072 \pm 448 \mathrm{pg} / \mathrm{mL})$ and those with no antenatal steroids $(821 \pm 510 \mathrm{pg} / \mathrm{mL}$; Fig. 2A). NT3 levels also were higher in subjects who received antenatal steroids $(311 \pm 133 \mathrm{pg} / \mathrm{mL})$ compared with those who received one dose $(260 \pm 48 \mathrm{pg} / \mathrm{mL})$ and those with no antenatal steroids $(214 \pm 90 \mathrm{pg} / \mathrm{mL})$. This difference did not reach statistical significance but showed a definite trend toward significance ( $p=0.055)$ by one-way ANOVA (Fig. 2B).

Neurotrophins and IVH. Significantly lower levels of BDNF were observed $(p=0.021)$ in cord blood specimens of subjects who subsequently had moderate to severe IVH (925 \pm $513 \mathrm{pg} / \mathrm{mL}$ ) compared with those who subsequently had mild IVH $(1470 \pm 550 \mathrm{pg} / \mathrm{mL})$ or a normal head ultrasound (1650 $\pm 674 \mathrm{pg} / \mathrm{mL}$; Fig. 3). We further analyzed gestational groups A and B. In group A (24-28 wk), cord blood BDNF levels
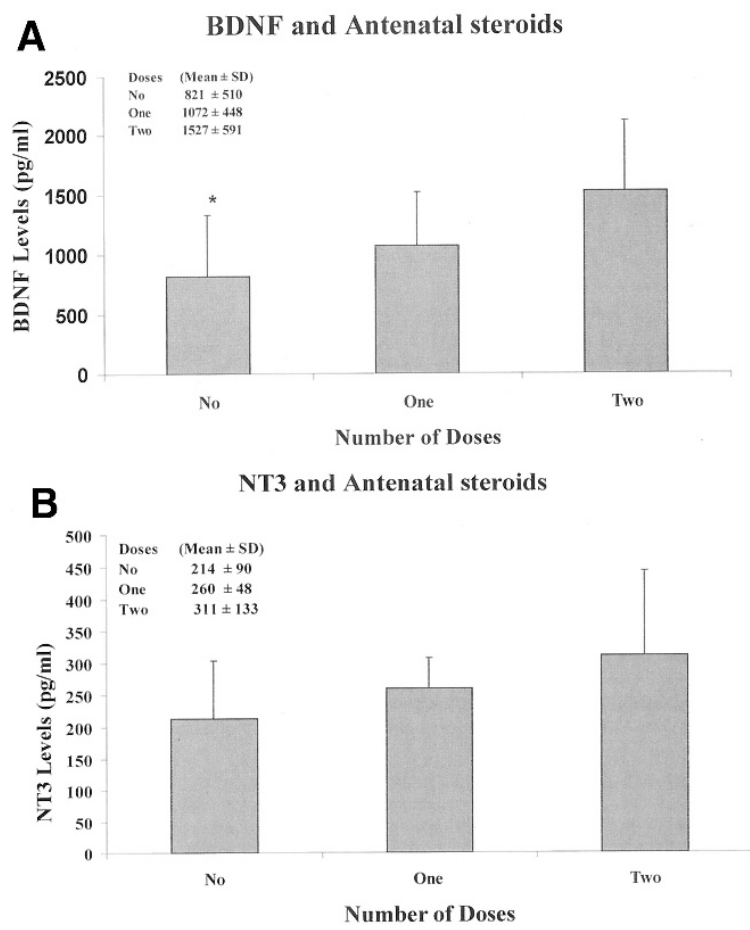

Figure 2. $A$, BDNF levels were higher in cord blood of infants when a complete course of antenatal steroids was given compared with those who received none $\left({ }^{*} p=0.029\right)$. $B$, Similarly, NT3 levels were higher in cord blood with a complete course of antenatal steroids although statistically not significant $(p=0.055)$. 
BDNF and IVH status

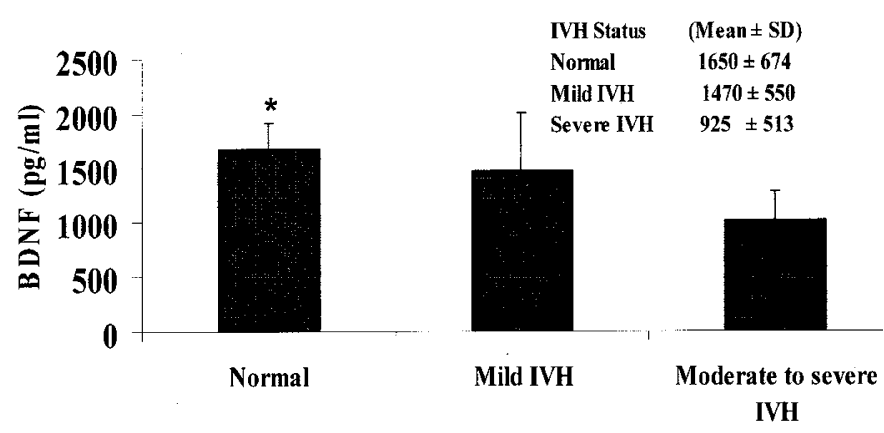

IVH status

Figure 3. BDNF levels were lower in cord blood of infants who subsequently had moderate to severe IVH compared with those who had normal head ultrasound scans $(* p=0.021)$.

were lower from infants who subsequently had severe IVH $(791 \pm 243 \mathrm{pg} / \mathrm{mL})$ compared with those from infants who had a normal postnatal head ultrasound scan $(952 \pm 562 \mathrm{pg} / \mathrm{mL})$. In group B (29-35 wk), cord blood BDNF levels were also lower from infants who subsequently had severe IVH (1249 \pm $233 \mathrm{pg} / \mathrm{mL}$ ) compared with those from infants who later had a normal head ultrasound scan $(1497 \pm 660 \mathrm{pg} / \mathrm{mL})$. Neither of these comparisons reached statistical significance. NT3 levels were higher in samples from infants who subsequently had normal head ultrasound scans $(291 \pm 126 \mathrm{pg} / \mathrm{mL})$ compared with mild IVH $(270 \pm 24 \mathrm{pg} / \mathrm{mL})$ and severe IVH $(238 \pm 89$ $\mathrm{pg} / \mathrm{mL}$ ). The one-way ANOVA did not show statistically significant differences between the groups $(p=0.793)$.

\section{DISCUSSION}

Neurotrophins are one group of factors responsible for neuroprotection. Multiple studies have demonstrated various roles for neurotrophins in the prevention of neuronal apoptosis and various neuronal functions in animal models and adult humans (32-34). In addition, neurotrophin levels have been quantified in infants born with hypoxic-ischemic encephalopathy (15) and in those with mental retardation and autism (35). Those studies demonstrated a rise in BDNF levels associated with both clinical situations. However, the presence and significance of BDNF and NT3 levels across the most important phase of neurodevelopment, i.e. during intrauterine life in humans, have not been studied previously.

It is interesting to note that BDNF levels increase with increasing gestational ages. Although BDNF and NT3 knockout animal models have demonstrated deficiencies mainly of the peripheral nervous system, their role in CNS development is only recently being elucidated using double knockout and overexpression experiments (36-38). BDNF has been shown to be responsible for developmental maturity of cortex and synaptic plasticity leading to refinement of connections (39). Increased expression of BDNF within the cortex has also been correlated to decreases in reelin expression (40). Reelin is an extracellular matrix molecule important in early cortical organization and development of the "inside-out" layering pattern. Decreased levels of reelin coincide with developmental matu-

rity and the elicitation of synaptogenesis (41). Because Volpe et al. established that human cortical gray matter increases by 4-fold between 29 and 35 wk gestation with increasing synaptic maturity, the increasing BDNF levels through this gestational age group may signify the role played by BDNF during this phase of human brain development (9).

NT3 is also an important neurotrophin for a developing brain (42). NT3 and BDNF have similar functions related to neuronal survival. In fact, they tend to complement each other in their actions (43). However, some of the functions are distinct to each molecule $(44,45)$. Despite all of these important functions, NT3 levels seem to remain unaltered, in our data, across the gestational age groups studied. This may be explained by the fact that neuronal responsiveness to the different neurotrophins changes with developmental changes, and, thus, compensatory changes in neurotrophin expression may be required for proper balance of their actions $(46,47)$. NT3 is important for multiplication of neuronal progenitors (32). Thus, NT3 levels may have been higher in an earlier gestational period, when progenitor multiplication is at its peak.

Prematurely born infants had better survival and neurologic outcome when antenatal steroids were given (7). Higher levels of both neurotrophins were observed when mothers were given a complete course of antenatal steroids. One possibility is that the improved developmental outcome may be mediated through increased availability of neurotrophins to these premature brains. Alternatively, it is also possible that improved neuronal maturity after antenatal steroids may induce increased neurotrophin secretion and further improvement in neurodevelopmental outcome. Thus, it may be interesting to study the presence and significance of these neurotrophins in premature infants postnatally.

Infants who had moderate to severe IVH on postnatal head ultrasound scans had lower BDNF levels compared with those who had normal head ultrasounds. Similarly, although there was no statistical significance, NT3 levels tended to be lower in subjects who subsequently developed severe IVH. These head ultrasound results were obtained postnatally between the third and seventh days of life. There may be various postnatal factors that could cause IVH between the birth and actual head ultrasound. Thus, we interpret these results cautiously. However, we suggest that lower BDNF and NT3 levels might reflect a more immature brain, which thus is more susceptible to moderate to severe bleeds.

Studying neurotrophins in relation to clinical variables mainly show nonsignificant differences across the variables. Female sex is associated with improved neurodevelopmental outcome among premature infants. Both neurotrophins are higher in girls compared with boys, although without statistical significance. BDNF levels are lower in the presence of maternal chorioamnionitis associated with increased incidence of cerebral palsy, again without statistical difference. Detailed studies are, however, warranted to investigate further the changes in neurotrophin levels across these clinical parameters.

NT3 levels did not change with gestational age like BDNF levels. However, NT3 levels show a trend similar to BDNF levels, both in infants who had subsequent IVH and in infants who received antenatal steroids. If studied further, these find- 
ings may prove useful for future assessment of neuronal maturity and/or neurodevelopmental outcome.

\section{CONCLUSION}

In conclusion, BDNF levels increase with increasing gestational ages in human umbilical cord blood. Higher neurotrophin levels were associated with a complete course of antenatal steroids. BDNF and NT3 levels were lower in infants with subsequent moderate to severe IVH. It would be interesting to evaluate postnatal neurotrophin levels from premature infants. It may also be interesting to look at the significance of these levels in relation to various insults that would alter final neurodevelopmental outcome.

Acknowledgments. We thank the employees of the clinical blood bank of the University of Kentucky, Lexington.

\section{REFERENCES}

1. Murphy DJ, Sellers S, MacKenzie IZ 1995 Case-control study of antenatal and intrapartum risk factors for cerebral palsy in very preterm singleton babies. Lancet 346:1449-1454

2. Verma U, Tejani N, Klein SR 1997 Obstetric antecedents of intraventricular hemorrhage and periventricular leukomalacia in the low-birth-weight neonate. Am J Obstet Gynecol 176:275-281

3. Gaudet LM, Smith GN 2001 Cerebral palsy and chorioamnionitis: the inflammatory cytokine link. Obstet Gynecol Surv 56:433-436

4. Acien P, Lloret G, Lloret M 1990 Perinatal morbidity and mortality in pregnancy hypertensive disorders: prognostic value of the clinical and laboratory findings. Int Gynaecol Obstet 32:229-235

5. Danielian PJ, Allman AC, Steer PJ 1992 Is obstetric and neonatal outcome worse in fetuses who fail to reach their own growth potential? Br J Obstet Gynaecol 99:452454

6. Billaud N, Lemarie P 2001 Negative effects of maternal smoking during the course of pregnancy. Arch Pediatr 8:875-881

7. Salokorpi T, Sajaniemi N, Hallback H, Kari A, Rita H, von Wendt L 1997 Randomized study of the effect of antenatal dexamethasone on growth and development of premature children at the corrected age of 2 years. Acta Paediatr 86:294-298

8. Lemons JA, Bauer CR, Oh W, Korones SB, Papile LA, Stoll BJ, Verter J, Temprosa M, Wright LL, Ehrenkranz RA, Fanaroff AA, Stark A, Carlo W, Tyson JE, Donovan EF, Shankaran S, Stevenson DK 2001 Very low birth weight outcomes of the National Institute of Child Health and Human Development Neonatal Research Network, January 1995 through December 1996. NICHD Neonatal Research Network. Pediatrics 107(1). Available at: www.pediatrics.org/cgi/content/full/107/1/e1

9. Inder TE, Huppi PS, Warfield S, Kikinis R, Zientara GP, Barnes PD, Jolesz F, Volpe JJ 1999 Periventricular white matter injury in the premature infant is followed by reduced cerebral cortical gray matter volume at term. Ann Neurol 46:755-760

10. Huppi PS, Warfield S, Kikinis R, Barnes PD, Zientara GP, Jolesz FA, Tsuji MK, Volpe JJ 1998 Quantitative magnetic resonance imaging of brain development in premature and mature newborns. Ann Neurol 43:224-235

11. Hetman M, Xia Z 2000 Signaling pathways mediating anti-apoptotic action of neurotrophins. Acta Neurobiol Exp (Warsz) 60:531-545

12. Tucker KL, Meyer M, Barde YA 2001 Neurotrophins are required for nerve growth during development. Nat Neurosci 4:29-37

13. Chao MV 2000 Trophic factors: an evolutionary cul-de-sac or door into higher neuronal function? J Neurosci Res 59:353-355

14. Takei N, Nawa H 1998 Roles of neurotrophins on synaptic development and functions in the central nervous system. Hum Cell 11:157-165

15. Korhonen L, Riikonen R, Nawa H, Lindholm D 1998 Brain derived neurotrophic factor is increased in cerebrospinal fluid of children suffering from asphyxia. Neurosci Lett 16:151-154

16. Cheng Y, Gidday JM, Yan Q, Shah AR, Holtzman DM 1997 Marked age-dependent neuroprotection by brain-derived neurotrophic factor against neonatal hypoxicischemic brain injury. Ann Neurol 41:521-529

17. Ferrer I, Krupinski J, Goutan E, Marti E, Ambrosio S, Arenas E 2001 Brain-derived neurotrophic factor reduces cortical cell death by ischemia after middle cerebral artery occlusion in the rat. Acta Neuropathol (Berl) 101:229-238
18. Karege F, Schwald M, Cisse M 2002 Postnatal developmental profile of brain-derived neurotrophic factor in rat brain and platelets. Neurosci Lett 328:261-264

19. Haddad J, Vilge V, Juif JG, Maitre M, Donato L, Messer J, Mark J 1994 Beta-nerve growth factor levels in newborn cord sera. Pediatr Res 35:637-639

20. Polin RA, Fox WW 1998 Fetal and Neonatal Physiology. WB Saunders, Philadelphia, pp 2106-2107

21. Kricka LJ 1994 Selected strategies for improving sensitivity and reliability of immunoassays. Clin Chem 40:347-357

22. Papile LA, Burstein J, Burstein R, Koffler H 1978 Incidence and evolution of subependymal and intraventricular hemorrhage: a study of infants with birth weights less than 1,500 gm. J Pediatr 92:529-534

23. Gibbs RS, Blanco JD, St Clair PJ, Castaneda YS 1982 Quantitative bacteriology of amniotic fluid from women with clinical intraamniotic infection at term. J Infect Dis $145: 1-8$

24. Yoon BH, Romero R, Park JS, Kim CJ, Kim SH, Choi JH 2000 Fetal exposure to an intra-amniotic inflammation and the development of cerebral palsy at the age of three years. Am J Obstet Gynecol 182:675-681

25. Williams RL, Creasy RK, Cunningham GC 1982 Fetal growth and perinatal viability in California. Obstet Gynecol 59:624-632

26. Campbell S, Newman GB 1971 Growth of the fetal biparietal diameter during normal pregnancy. J Obstet Gynaecol Br Commonw 78:513-519

27. Mongelli M, Wilcox M, Gardosi J 1996 Estimating the date of confinement: ultrasonographic biometry versus certain menstrual dates. Am J Obstet Gynecol 174:278 281

28. Tunon K, Eik-Nes SH, Grottum P, Von During V, Kahn JA 2000 Gestational age in pregnancies conceived after in vitro fertilization: a comparison between age assessed from oocyte retrieval, crown-rump length and biparietal diameter. Ultrasound Obstet Gynecol 15:41-46

29. Ballard JL, Novak K, Driver M 1979 A simplified score for assessment of fetal maturation of newly born infants. J Pediatr 95:769-774

30. Ballard JL, Khoury JC, Wedig K, Wang L, Eilers-Walsman BL, Lipp R 1991 New Ballard Score expanded to include extremely premature infants. J Pediatr 119:417423

31. Alexander GA, de Caunes F, Hulsey TC, Tompkins ME, Allen M 1992 Validity of postnatal assessments of gestational age: a comparison of the method of Ballard et al. and early ultrasonography. Am J Obstet Gynecol 166:891-895

32. Henderson CE 1996 Role of neurotrophic factors in neuronal development. Curr Opin Neurobiol 6:64-70

33. Barde YA 1994 Neurotrophins: a family of proteins supporting the survival of neurons. Prog Clin Biol Res 390:45-56

34. Lewin GR, Barde YA 1996 Physiology of the neurotrophins. Annu Rev Neurosci 19:289-317

35. Nelson KB, Grether JK, Croen LA, Dambrosia JM, Dickens BF, Jelliffe LL, Hansen RL, Phillips TM 2001 Neuropeptides and neurotrophins in neonatal blood of children with autism or mental retardation. Ann Neurol 49:597-606

36. Conover JC, Yancopoulos GD 1997 Neurotrophin regulation of the developing nervous system: analyses of knockout mice. Rev Neurosci 8:13-27

37. Ernfors P, Kucera J, Lee KF, Loring J, Jaenisch R 1995 Studies on the physiological role of brain-derived neurotrophic factor and neurotrophin-3 in knockout mice. Int J Dev Biol 39:799-807

38. Farinas I, Jones KR, Backus C, Wang XY, Reichardt LF 1994 Severe sensory and sympathetic deficits in mice lacking neurotrophin-3. Nature 23;369:658-661

39. Lu B, Figurov A 1997 Role of neurotrophins in synapse development and plasticity. Rev Neurosci 8:1-12

40. Ward NL, Hagg T 2000 BDNF is needed for postnatal maturation of basal forebrain and neostriatum cholinergic neurons in vivo. Exp Neurol 162:297-310

41. Ringstedt T, Linnarsson S, Wagner J, Lendahl U, Kokaia Z, Arenas E, Ernfors P, Ibanez CF 1998 BDNF regulates reelin expression and Cajal-Retzius cell development in the cerebral cortex. Neuron 21:305-315

42. Chalazonitis A 1996 Neurotrophin-3 as an essential signal for the developing nervous system. Mol Neurobiol 12:39-53

43. ElShamy WM, Ernfors P 1997 Brain-derived neurotrophic factor, neurotrophin-3, and neurotrophin-4 complement and cooperate with each other sequentially during visceral neuron development. J Neurosci 17:8667-8675

44. Coppola V, Kucera J, Palko ME, Martinez-De Velasco J, Lyons WE, Fritzsch B, Tessarollo L 2001 Dissection of NT3 functions in vivo by gene replacement strategy Development 128:4315-4327

45. Postigo A, Calella AM, Fritzsch B, Knipper M, Katz D, Eilers A, Schimmang T, Lewin GR, Klein R, Minichiello L 2002 Distinct requirements for TrkB and TrkC signaling in target innervation by sensory neurons. Genes Dev 16:633-645

46. Ciccolini F, Svendsen CN 2001 Neurotrophin responsiveness is differentially regulated in neurons and precursors isolated from the developing striatum. J Mol Neurosci $17: 25-33$

47. Oppenheim RW 1996 Neurotrophic survival molecules for motorneurons: an embarrassment of riches. Neuron 17:195-197 